\title{
WHOLE PLANT ADIANTUM CAPILLUS-VENERIS LINN. EXTRACT AS AN ANTI-COVID-19 THERAPY.
}

Lina M. Hendawy

Faculty of medicine and surgery, October 6 university, Egypt.

\begin{abstract}
Coronavirus disease (COVID-19) is an infectious disease caused by a newly discovered strain of Corona viruses (SARS-CoV-2). The disease causes mild to severe symptoms, mainly respiratory. Some patients can develop pneumonia, severe acute respiratory syndrome, kidney failure and even death. Any patient can develop mild to severe illness, but old age and severe underlying medical conditions like chronic lung diseases, diabetes, obesity, etc. seem to be higher risk factors for developing more serious complications from COVID-19. There is no specific treatment for COVID-19. However, many of the symptoms can be treated according to the patient's clinical condition. Adiantum capillus-veneris (Maidenhair fern) is a medicinal herb of the family Pteridaceae. The plant extract showed a potential efficacy as ancient physicians used it for curing different diseases. In modern medicine, the plant was proven to possess a pharmacological efficacy to treat many symptoms similar to that caused by COVID-19 and its underlying medical conditions. Herbal agents extracted from Adiantum capillus veneris is widely used for the treatment of COVID-19 in Egypt, but Unfortunately, specific preclinical and clinical trials to evaluate the effects of the herbal immunoregulators in COVID19 patients have not been conducted. However, Certain natural compounds are proven here to be possibly effective for the treatment of COVID-19 symptoms based on general concepts from previous experiments. Meanwhile, people believe that consuming herbal immunomodulators can prevent or even cure COVID-19, this review is done to discuss the pros and cons of utilising the extract of Adiantum capillus veneris during COVID-19 pandemic, draw conclusions, and make recommendations of modern therapeutic application of an extract-based drug to treat symptoms of patients with COVID-19.

\section{Introduction}

A pneumonia of unknown cause, first reported in Wuhan, China to the World Health Organization country office in December 2019 was declared as a public health emergency of international concern in January 2020. In February 2020, the World Health Organisation announced a name for a new coronavirus outbreak: COVID-19 [1]. SARS-CoV-2 viral infection has variable effects on different people. According to the international guidelines announced by the World Health Organisation, most common symptoms of COVID-19 include fever, dry cough and tiredness. Less common symptoms include body aches, headache, sore throat, diarrhea, skin rash and others. Although most patients develop mild to moderate symptoms, others can develop serious symptoms that can be severe enough to cause death. The mechanism of how the viral infection affects people differently is still unknown. However, factors like old age, diabetes, obesity, chronic lung diseases, androgenic disorders and other comorbidities are thought to increase the risk of developing a severe form of the disease. Though available vaccines that hold future promise, infection control and chemotherapy remain the primary weapons for reducing the burden of the disease in individuals and populations. There are still no drugs or therapeutics approved by the Food and Drug Administration (FDA) to treat or prevent COVID-19. Current clinical procedure includes prevention and control of infection by supportive care including supplemental oxygen and mechanical ventilatory support depending on patients' clinical conditions [2]. 
On the other hand, Adiantum capillus-veneris, Maidenhair fern, a herb of the class Pteridopsida, family Pteridaceae, Adiantaceae, has medicinal parts like fronds, rhizomes and roots that have various medicinal properties [3]. The plant has a cosmopolitan distribution and is found in various shady and moist regions throughout the World [4,5]. Scientists assessed the plant extract chemical composition for its numerous pharmacological effects after being used for curing different diseases by ancient physicians. The plant was proven to possess anti-inflammatory, antioxidant, analgesic, antibacterial, antifungal, antidiarrheal, antispasmodic, anticonvulsant, hypoglycemic anti-diabetic, hypocholesterolemic, anti-obesity, goitrogenic, anti-thyroidal, anti-asthmatic, anti-androgenic alopecia, as well as diuretic, anti-lithiasic, detoxifying and many other effects.

Dealing with many symptoms similar to that which are caused by the current COVID-19 disease and the underlying risk factors for developing severe illness, the plant is used by the public as a herbal treatment for COVID-19 patients in Egypt. People competitively shopped for the herbal products to prevent or even cure COVID19 patients. Unfortunately, this community behaviour was undertaken without a solid research based on the plant effects on COVID-19.

This review explains in detail the symptoms of COVID-19 and how active compounds of Adiantum capillus veneris products might prevent or cure the symptoms of COVID-19. It also will discuss the safety aspects of the natural compounds of the herb and provide recommendations for both the community and clinicians what makes the plant extract a potential candidate for starting a Maidenhair fern Clinical Therapy (MCT)

\section{Active ingredients}

Adiantum capillus-veneris L. extract includes:

- Flavonoids: astragalin, isoquercitrin, kaempferol-3-sulfate, naringin, nicotiflorin, populnin, procyanidin, prodelphinidin, quercetin, quercetin-3-O-glucoside, querciturone and quercetin-3-O-rutinoside (rutin) [6-9].

- Triterpenoids: 3-methoxy-4-hydroxy filicane, 3,4-dihydroxyflavone, 30-normethyl fernen-22-one (capillirone, 1), hopan-3 $\beta$-ol (capillirol B, 2)

hydroxyadiantone,21-hydroxy adiantone, isoadiantone, isoglaucanone, isoadiantol-B, hdoxyhopane, adiantoxide, adian5-en-3a-ol, adian-5(10)-en-3a-ol, olean-18-en-3-one, olean-12-en-3-one, pteron-14-en-7a-ol, hop- 22(29)ene, neohop-12-ene, filic-3-ene , 7-fernene, ferna-7, 9(11)-diene, fern-9(11)-ene, fern-9(11)-en-28-O, Fern-9(11)-en-12-one, fern-9(11)-en-12- beta-ol, fern9(11)-en$3 a-o l$ and fern-7-en-3a-ol [10-23].

- Four sulphate esters of hydroxycinnamic acid-sugar derivatives:

1-caffeylgalactose-3-sulphate, 1-caffeylgalactose-6-sulphate,

1-p-coumarylglucose-6-sulphate and 1-p-coumarylglucose-2-sulphate [24].

- Sterols: beta sitosterol, stigmasterol and capesterol [23].

- Aoleananes, carbohydrates, alicyclics, phenylpropanoids and carotenoids, $\mathrm{Mg}, \mathrm{Mn}$, $\mathrm{Fe}, \mathrm{Co}, \mathrm{Na}, \mathrm{Ni}, \mathrm{Cu}, \mathrm{Zn}$ and mainly $\mathrm{Ca}$ and $\mathrm{K}$;Fibers, fats and waxes [6];

\section{Extraction}

Leaves contain $24.00 \%$ water extractable matter, $8.3 \%$ moisture extractable matter and $11.44 \%$ ethanol extractable matter [6].

The following table shows the total phenolics and total flavonoids in the leaves in $(\mathrm{mg} / 100 \mathrm{~g})$ in aqueous, methanolic and ethanolic extracts respectively [25]: 


\begin{tabular}{|l|l|l|}
\hline & Total phenolics & Total flavonoids \\
\hline Aqueous extract & $224.76 \pm 9.75$ & $49.62 \pm 0.875$ \\
\hline Methanolic extract & $156.34 \pm 9.70$ & $78.18 \pm 1.741$ \\
\hline Ethanolic extract & $36.53 \pm 3.65$ & $50.15 \pm 4.79$ \\
\hline
\end{tabular}

Pharmacological actions of the extract in relation to symptoms of COVID-19 :-Anti-inflammatory:

The systemic cytokine profiles that are observed in patients with severe COVID-19 show similarity to cytokine release syndromes that are caused by overproduction of cytokines such as IL-6, tumour necrosis factor (TNF) and inflammatory chemokines which include CC-chemokine ligand, CCL3 and CXC-chemokine ligand 10 (CXCL10) and soluble a-chain of the interleukin 2 (IL-2) receptor. This has led to the hypothesis that dysregulated activation of the mononuclear phagocyte (MNP) compartment leads to COVID-19-associated hyper-inflammation and cytokine storm [26]. Trials to block IL-6 signalling in a subset of patients across the world showed some clinical benefits. A study reported a clear benefit in 15 of 20 patients treated with IL- 6 blockade, leading to FDA approval of IL-6 blockade in patients with COVID-19 [27].

In vitro, the anti-inflammatory activity of the ethanolic extract of Adiantum capillus veneris appeared to have suppressing effect on nuclear factor kappa B activation leading to a significant inhibitory effect on the production of inflammatory cytokine in human monocytes lipopolysaccharide-induced prostaglandin E2, interleukin 6 (IL-6) and tumor necrosis factor (TNFa) generation with an IC50 less than $50 \mu \mathrm{g} / \mathrm{ml}$ [28]. Moreover, it has a cell-specific pattern on NF-KB gene transcription by blocking luciferase expression and it also downregulates IKKa/ $\beta$ phosphorylation by selective abrogatation of IL-8 transcription at a dose of $200 \mu \mathrm{g} / \mathrm{mg}$ [29]. In hind paw edema test in rats, at a dose of $300 \mathrm{mg} / \mathrm{kg}$, the ethyl acetate fraction of the plant ethanolic extract has a better anti-inflammatory activity than that of the standard drug Indomethacin [29]. The anti-inflammatory activity of the ethanolic extract and all its fractions against COVID-19-associated hyper-inflammation and cytokine storm is expected to be mainly related to the inhibition of NO release and reduction in TNF- $\alpha$ level.

\section{-Antioxidant:}

At the cellular level under hypoxic conditions that occur in respiratory diseases, the reactive oxygen species (ROS) and reactive nitrogen species (RNS) are continuously generated by the mitochondrial metabolism and inflammatory cells in the case of diseases that are caused by pathogens that include virus replication such as COVID-19 [30]. Therefore, international guidelines make recommendations for the dietary antioxidants in supportive treatment and prevention of COVID-19. In vitro, through DPPH test, the ethanolic extract from Adiantum capillus-veneris Linn exerted a good antioxidant activity compared to ascorbic acid with a low value of IC50 (0.3986 mg/gm). by the same assay ultrasonic-assisted flavonoid extract of the plant exhibited a chelating capability on ferrous ions, scavenging capacity on superoxide anion and reducing power tests. The plant essential oil phytoconstituents like carvacrol and thymol are responsible for its antioxidant capacity [31]. Aqueous and butanol fractions have significant protection against the damaging of fibroblasts by oxygen free radicals [32]. In vitro, a 18 hour pretreatment with the extract of the plant leaves inhibits peroxidation of lipids and significantly enhances glutathione (GSH) content and antioxidant 
enzymes activity in peripheral blood lymphocytes hydrogen peroxide $(\mathrm{H} 2 \mathrm{O} 2)$-induced oxidative damage [33]. In vivo, the plant showed more potent antioxidant activity compared to some synthetic antioxidants such as ascorbic acid, EDTA and BHT. Total flavonoids from Adiantum capillus-veneris showed a high scavenging activity on hydroxyl radicals in peripheral blood lymphocytes induced oxidative damage [34-35]. Antioxidants have a potential role in the treatment of respiratory diseases and the plant antioxidant capacity against COVID-19 is referred to be due to its direct potential in scavenging free radicals and modulating the antioxidant defense system.

\section{-Analgesic and antinociceptive:}

The early symptoms of COVID-19 include generalised muscle and body-aches [36]. The analgesic effect of the ethanolic extract from Adiantum capillus-veneris and especially its ethyl acetate fraction $(p<0.01)$ was confirmed through tail flick method and writhing test. The results revealed significant analgesic action with insignificant gastric ulceration compared to standard anti-inflammatory, antipyretic and analgesic drugs as Ibuprofen [ 9 , 29,37 ] and its 4- $\alpha$ - hydroxyfilican-3-on fraction exhibited a significant anti-nociceptive activity [38].

\section{-Antimicrobial co-infection:}

Co-infections occur within one to four days after the onset of COVID-19 infection. Microbial co-infection increases the risk of disease severity in humans. Patients with fungal co-infections, bacterial-fungal co-infections and viral co-infections were among the highest severe cases of COVID-19. 242 among 257, about $94.2 \%$ of laboratory-confirmed COVID-19 cases got co-infection with one or more pathogens. When tested for 39 respiratory pathogens by a real-time PCR, 24 out of the 29 respiratory pathogens were confirmed among patients. However, Streptococcus pneumoniae followed by Klebsiella pneumoniae and Haemophilus influenzae were the most common pathogens confirmed among COVID-19 patients [39].

Different extracts of all used parts of Adiantum capillus veneris displayed potent antibacterial and antifungal properties [40]. Methanolic extracts of four important Adiantum species were evaluated for antibacterial and antifungal effects. Among these species, A.capillus-veneris showed a potent antibacterial properties. The methanolic extract of Adiantum capillus-veneris was tested for its antimicrobial activity against five gram positive (including multi-resistant Staphylococcus aureus), six gram negative bacteria and eight fungal strains. Broad antimicrobial properties and maximum zone of inhibition against Staphylococcus, Klebsiella pneumoniae, Pseudomonas aeruginosa, Proteus vulgaris, Agrobacterium tumefaciens, Salmonella arizonae, Salmonella typhi, Providencia, Candida,Vibrio cholera, Shigella, Helicobacter pylori and Escherichia coli with and a very low minimum inhibitory concentration (mic) value between 0.5 and $2 \mathrm{mg} / \mathrm{ml}$ was confirmed [41]. The water extract of the species was very potent against all bacteria strains. In vitro, the ethanolic extract of the plant possesses antiviral properties [42]. The plant extract antimicrobial capacity against the virus and multidrug resistant (MDR) bacterial strains associated with COVID-19 was confirmed through tissue culture and disc diffusion method respectively.

\section{-Neuropharmacological effect:}

Coronaviruses have positive tropism to invade the central nervous system and cause neurological pathologies under certain conditions. In most human coronavirus infections(OC-43, 229E, MERS and SARS), neuroinvasion is reported. In patients affected by COVID-19, neurological symptoms including headache, dizziness, stroke, myalgia and anosmia, encephalitis, encephalopathy, necrotising hemorrhagic encephalopathy, rhabdomyolysis, Guillain-Barre syndrome and epileptic seizures were reported [43]. 
The indication of different Adiantum capillus veneris extracts in patients with

COVID-19-associated neurological symptoms is due to its anticonvulsant effect and the neurological depressant profile of the active ingredients. In PTZ-induced convulsion model, The plant extract could reduce the period of seizures and prolong onset of action. In the MES-induced seizure model, it could decrease the time of different phases of seizure. In a forced swim test in mice, the plant revealed depressant property by prolonging immobility time [44]. Shikimic acid isolated from the plant extract is responsible for the neuroprotective activity. It decreases middle cerebral artery thrombosis-induced focal cerebral ischemic injury [45].

\section{-Antidiarrheal spasmolytic:}

Diarrhea is the most common GIT manifestation of COVID-19 and the early symptom of COVID-19 in $19 \%$ of patients and lasted for 5.4 days ( \pm 3.1 days) in average, with $4.3( \pm 2.2)$ daily frequent bowel movements and SARS-CoV-2 RNA frequently detected in their fecal samples $(73.3 \%)$. Furthermore, the recovery after the onset of symptoms takes a longer time in patients with digestive symptoms (16 days) compared to (11.6 days) in patients with respiratory symptoms only [46].

The indication of Adiantum capillus veneris extract in COVID-19-associated GIT disorders is due to the significant antidiarrheal and antispasmodic capacity. The antidiarrheal effect of Adiantum capillus-veneris leaves was confirmed through castor oil-induced diarrhea in mice. The antispasmodic activity of the plant extracts was confirmed through its inhibitory effect on $\mathrm{K}+$-induced contraction in isolated rabbit jejunum [47].

\section{Controlling COVID-19 disease in high risk groups :- -Diabetic patients:}

The compromised immune system and an environment of elevated blood glucose for the virus as well as the presence of possible diabetes complications make diabetic patients with COVID-19 among high risk groups to develop severe illness and require a longer recovery period [48].

Extract from Adiantum capillus veneris, prepared by boiling the dried parts with water, reduced glucose-induced hyperglycemia in mice when it was given orally at a dose of (25 $\mathrm{mg} / \mathrm{kg}$ ). The alcoholic extract of Adiantum capillus-veneris exhibited significant hypoglycaemic effect in rabbits, onset of action started after $30 \mathrm{~min}$ of administration and lasted for 4 hours [9]. Aqueous and methanolic extracts Improved the fasting blood sugar level with low side effects in streptozotocin-induced diabetic rat model [49]. Due to insulin-like constituents in the species, the plant extract significantly affects pancreas activity for amylase secretion and reduces the blood glucose Level [50]. The species also revealed anti-hyperglycemic properties compared to the standard drug Acarbose [51]. An ointment containing the plant extract cured wounds in diabetic rats [52].

\section{-Obesity:}

Obesity plays an important role in the pathogenesis of COVID-19 infection. 88\% of 112 patients reported with obesity were among the highest severe COVID-19 cases who died compared to $19 \%$ who survived [53]. Among 124 patients admitted to an intensive care unit with COVID-19 50\% were with obese BMI. The more BMI of the patient, the more the need for mechanical ventilation [54].

Water extract of Adiantum capillus-veneris exhibited potent hypocholesterolemic effect by the reduction of serum total cholesterol (TC) levels with no change in HDL level. TC/HDL atherogenic index was normalized in rats treated with a preparation of the plant [55]. In vitro, the plant has significant inhibitory effect on phospholipase compared to standard drug Orlistat [51]. 


\section{-Renal complications:}

severe cases of COVID-19 reported signs of kidney damage including high levels of acidosis, protein in urine and abnormal blood work even in cases with no history of underlying renal problems. Almost $30 \%$ of hospitalized patients with COVID-19 in China and New York developed moderate or severe kidney dysfunction or even required dialysis [56]. After a 14 day therapy with the ethanolic extract from Adiantum capillus-veneris Linn at a dose of $500 \mathrm{mg} / \mathrm{kg}$, a significant nephroprotective activity was revealed [57]. The plant improved the renal pathological features associated with systemic Candida Albicans infection in mice [78]. Besides, the plant astragalin anti-proliferative activity inhibited matrix over-synthesis and proliferation of human mesangial cells which is supposed to prevent progression of chronic renal disease. The hydro-alcoholic extract of the plant caused a significant reduction in the number of crystals and serum levels of calcium, phosphorus and blood urea [58]. The plant also affected crystallization, crystal aggregation, sizes and numbers of crystals in vitro [59]. The plant extracts raise urinary output at low doses.

\section{-Androgenic disorders-related complications:}

Concentration of testosterone in plasma is reduced by age and by comorbidities like diabetes and obesity [60] that are highly prevalent in COVID-19 patients. Vast majority of men with COVID-19 cases admitted to intensive care units had low plasma testosterone levels that can induce cytokine storms which in turn can be fatal [61]. $71 \%$ out of 41 COVID-19 cases with bilateral pneumonia had clinically a significant androgenic alopecia [62]. About $79 \%$ of the men and $42 \%$ of the women involved in the study of 175 COVID-19 cases had signs of androgenic alopecia [63]. Therefore, COVID-19 patients with androgenic disorders seem to be more likely to need hospitalization and more likely to develop serious complications of the disease.

Through a testosterone-induced alopecia model, the ethanolic extract of Adiantum capillus-veneris displayed a potent hair tonic effect on anagen/telogen ratio and follicular density on albino mice. This hair growth-promoting activity was evaluated in Adiantum capillus-veneris-treated group in comparison to testosterone and finasteride treated groups respectively as described in following table:

\begin{tabular}{|l|l|l|}
\hline Animal group & $\begin{array}{l}\text { The follicular density } \\
\text { (follicles/mm) }\end{array}$ & Anagen/telogen ratio \\
\hline $\begin{array}{l}\text { Adiantum capillus } \\
\text { veneris-treated }\end{array}$ & $1.92 \pm 0.47$ & $0.92 \pm 0.06$ \\
\hline Testosterone-treated & $0.23 \pm 0.03$ & $0.23 \pm 0.03$ \\
\hline Finasteride-treated & $2.05 \pm 0.49$ & $1.12 \pm 0.06$ \\
\hline
\end{tabular}

As observed, after 21 days, the animal group treated with Adiantum capillus-veneris showed less hair loss compared to the group treated with testosterone only and anagen/telogen ratio was significantly affected [64].

\section{-Chronic Lung disease:}

People with underlying chronic lung disease, including asthma, were at a higher risk of hospitalization for COVID-19 in the United States [65] and more likely to develop multisystem inflammatory syndrome that is temporally related to COVID-19 in children and adolescents [66]. 
Anti-asthmatic effect of the ethanolic extract from Adiantum capillus-veneris leaves was confirmed through histamine aerosol-induced asthma in guinea pig [67]. According to usage history, most important indication of $A$. capillus veneris was mainly for respiratory tract conditions as anti-productive cough, anti-dyspnea, anti-tuberculosis and anti-asthmatic agent [68-71].

\section{Safety and adverse effects}

The plant extracts have no inhibitory effect on Aryl Hydrocarbon Hydroxylase $(\mathrm{AHH})$ and Epoxide Hydrolase (EH) enzymes which accelerate conversion of carcinogenic components into active compounds [72]. It has a safe contact with eyes as ancient physicians applied the active ingredient as eye drops to control the fistula lacrymalis [73]. It has a safe contact with intact skin as ancient physicians applied the active ingredient topically as an ointment [74]. It is also safe on broken skin as the extract of the plant increases angiogenesis and proliferation of endothelial cells and protects fibroblasts from damage by oxygen free radicals [75]. It also cured wounds in diabetic rats [76]. Discomfort (eg, burning, itching) is not expected or usually disappear after a short time as it reduces severity of pre-existing dermatitis and prevents development of atopic dermatitis [77]. There is no risk on patients with underlying gastric ulceration and reflux esophagitis compared to some standard anti-inflammatory drugs as the ethanolic extract and its fractions don't cause ulcers in the stomach at a dose of $900 \mathrm{mg} / \mathrm{kg}$ body weight [29]. Moreover, the plant extract has gastroprotective properties by inhibiting inflammatory cytokine production, gastric acid secretion, intracellular calcium mobilization and oxidative stress. The effect on the ability to drive and use machines has not been studied in humans, but according to side effect and toxicity profile obtained on animal studies, no major behavioral change is expected as no acute toxicity, restlessness, seizure or piloerection were noticed in mice at doses of 1, 3 and $7 \mathrm{~g} / \mathrm{kg}$ up to 6 hours after oral administration [49]. The plant extract may have pungent taste that is almost not felt with no specific flavor [78].

Accordingly, on proper dosage, the active ingredient seems to be significantly safe and have no health hazards. No adverse events were reported for this plant in modern phytotherapy. However, The plant exhibited to have spleen protective function in mice and it could normalize the LPS-induced elevated spleen index at $200 \mu \mathrm{g} / \mathrm{mg}$ [80] and could also reduce the colony-forming units (CFU) of Candida albicans in the spleen [81], avoid indication in patients susceptible to spleen damage [79] as from traditional report, the plant is considered harmful to spleen so it's not recommended. On the other hand, this adverse event is traditionally reduced by combination with Pistacia lentiscus resin (mastic) or Viola odorata flower (English violet) [68-70]. The plant medication is also contraindicated in women with estrogen-positive cancers as it probably has estrogen-like effects [25]. There is no clinical data on direct and indirect possible toxicity effects of the plant extract on pregnancy, embryonic, fetal development, postnatal development or breast feeding. However, The medication is contraindicated in pregnant women or couples seeking pregnancy as it may have abortive action and prevent conception as the plant extract ingredient of the drug is traditionally believed to stimulate the uterus and promote menstruation, additionally and animal studies indicated anti-implantation effect [25]. It's better to avoid indication in patients with overactive thyroid gland as in toxic adenoma, multinodular goiter and Graves' diseases. Although the plant extract decreased size of the gland in animal studies, thyroid peroxidase action, antioxidant enzymes, T4 and T3 serum levels increased and TSH serum level strongly decreased [82].

\section{Toxicity}


No acute oral toxicity is expected. In vivo, methanolic, aqueous and ethanolic extracts of the plant have no major behavioral changes or lethality at acute dosage of $2000 \mathrm{mg} / \mathrm{kg}$ in mice $[82,83]$. However, the medication should be administered with caution at designed therapeutic doses according to clinical conditions taking into consideration the hypoglycemic, hypocholesterolemic, goitrogenic, anti-calcium and double effect on diuresis of the plant extract. High dosage can reverse the diuretic effect and reduce the urinary output significantly [81].This plant should be used with caution in patients with diabetes and patients with hypoglycemia and monitor their blood sugar levels accordingly.

\section{Conclusion}

The fern species Adiantum which is Maidenhair was employed for numerous medicinal purposes by the Pharaohs on Ancient Land of Egypt. Nowadays and after thousands of years, Adiantum capillus-veneris has showed to be a promising effective and safe candidate for development of a novel drug to treat many symptoms associated with COVID-19 with its wide range of chemical constituents and numerous pharmacological effects that is expected to be useful if clinically applied in adequate therapeutic dosages.

\section{References}

1. Worldhealthorganization.Coronavirusdisease2019.[database on the internet]. https://www.who.int/emergencies/diseases/novel-coronavirus-2019/events-as-they-happen.

2. Center for disease control and prevention/Coronavirusdisease2019. [database on the internet]. https://www.cdc.gov/coronavirus/2019-ncov/hcp/therapeutic-options.html.

3. Plant Propagation Protocol for Adiantum capillus-veneris. ESRM 412-Native Plant Production, http://courses.washington.edu/esrm412/protocols/ADCA.pdf

4. The Plant List [database on the Internet] (2013). http://www.theplantlist.org/

5. L H. Evaluation of Antibacterial, Antioxidant and Toxicological Activity of Crude Extracts of Adiantum capillus-veneris, Blumea lacera, Cassia alata, and Cissus quadrangularis. BRAC, Department of Mathematics and Natural Sciences; 2011.

6. Akabori $Y$ and Hasagava M. Flavonoid pattern in the pteridaceae II , Flavoniod consistituents in the frounds of Adiantum Capillus-veneris and A. Cuneatum [J]. Shokubutsugaku Zasshi, 1969, 82294-297.

7. Cooper-Driver G and Swain FLS. Phenolic chemotaxonomy and phytogeography of Adiantum. Botanical Journal of the Linnean Society, 1977, 74.

8. Imperato F. Kaempferol 3-sulphate in the fern Adiantum capillus-veneris. Phytochemistry, 21, 1982, 2158-2159.

9. Ibraheim ZZ, Ahmed AS, Gouda YG. Phytochemical and biological studies of Adiantum capillus-veneris L. Saudi Pharm J 2011; 19: 65-7487-9, 1-10.

10. Haider S, Kharbanda C, Alam MS, Hamid H, Ali M, Alam M, et al. Anti-inflammatory and antinociceptive activities of two new triterpenoids from Adiantum capillus-veneris Linn. Nat Prod Res 2013; 27: 2304-2310.

11. Nakane T, Maeda Y, Ebihara H, Arai Y, Masuda K, Takano A, et al. Fern constituents: triterpenoids from Adiantum capillus-veneris. Chem Pharm Bull (Tokyo) 2002; 50: 1273-1275.

12. Berti G, Bottari F and Marsili A. Structure and stereochemistry of a triterpenoid epoxide from Adiantum capillus-veneris. Tetrahedron, 25, 1969, 2939-2947.

13. Shinozakia J, Shibuyaa M, Masudab K and Ebizukaa Y. Squalene cyclase and oxidosqualene cyclase from a fern. FEBS Letters, 582, 2008, 310-318.

14. Shiojima K, Arai Y, Masuda K, Takase Y, Ageta T and Ageta H. Mass spectra of pentacyclic triterpenoids. Chem Pharm Bull, 40, 1992, 1683-1690. 
15. Shiojima K, Sasaki Y, Ageta H. Fern constituents: triterpenoids isolated from the leaves of Adiantum pedatum. 23Hydroxyfernene, glaucanol A and filicenoic acid. Chem Pharm Bull, 41, 1993, 268-271.

16. Shiojima K, Masuda K, Suzuki H, Lin T, Ooishi Y and Ageta H. Composite constituents: Forty two triterpenoids including eight novel compound isolated from Picris hieracioides subsp. Japonica Chem Pharm Bull, 43, 1995, 1634-1639.

17. Ageta H, Shiojima K, Arai Y, Suzuki H and Kiyotani T. NMR spectra of triterpenoids. II. Hopenes and migrated hopenes. Chem Pharm Bull. 1994; 42: 39-44.

18. Nakane T, Aray Y, Masuda K, Ishizaki Y, Ageta H and Shiojima K. Fern constituents: six new triterpenoid alcohols from Adiantum capillus-veneris. Chem Pharm Bull, 47, 1999, 543-547.

19. Abdel-Halim OB, Ibraheim ZZ and Shiojima K. Oleanane triterpenes from Adiantum capillus-veneris growing in Egypt. Alex J Pharm Sci, 16, 2002, 87-92.

20. Takahisa N, Yoshiko M, Hideharu E, Yoko A, Kazuo M, Akihito T, Hiroyuki A, Kenji S, Shao-Qing CAI, and Osama BA. Fern Constituents: Triterpenoids from Adiantum capillus-veneris. Chem Pharm Bull, 50(9), 2002, 1273-1275.

21. Ansari R and Ekhlasi-Kazaj K. Adiantum capillus-veneris. L: Phytochemical constituents, traditional uses and pharmacological properties: A review. J Adv Sci Res, 3(4), 2012, 15-20. 22. Pan $\mathrm{C}$, Chen YG, Ma XY, Jiang JH, He F and Zhang Y. Phytochemical constituents and pharmacological activities of plants from the genus Adiantum: A review. Tropical Journal of Pharmaceutical Research, 10(5), 2011, 681-692.

23. Johnson CB. The Useful Plants of Great Britain. London, 1867.

24. Marino A, Elberti MG, Cataldo A. [Phytochemical investigation of Adiantum capillus veneris]. Boll Soc Ital Biol Sper 1989; 65: 461-463.

25. Tropical plants database, Avenca, (Adiantum capillus-veneris), U1Ea7IWSzNM, 2013. http://www.raintree.com/avenca.htm\#.

26. Mehta $P$, et al. COVID-19: consider cytokine storm syndromes and immunosuppression. Lancet. 2020;395:1033-1034. Doi: 10.1016/S0140-6736(20)30628-0.Schulert GS, Grom AA. Pathogenesis of macrophage activation syndrome and potential for cytokine-directed therapies. Annu. Rev. Med. 2015;66:145-159. Doi: 10.1146/annurev-med-061813-012806. 27. Xu, X. et al. Effective treatment of severe COVID-19 patients with tocilizumab. Proc. Natl Acad. Sci. USA10.1073/pnas.2005615117 (2020).

28. Yuan Q, Zhang X, Liu Z, Song S, Xue P, Wang J and Ruan J. Ethanol extract of Adiantum capillus-veneris $L$. suppresses the production of inflammatory mediators by inhibiting NF-kB activation. J Ethnopharmacol, 147(3), 2013, 603-611

29. Haider S, Nazreen S, Alam, MM, Gupta A, Hamid H and Alam MS. Anti-inflammatory and anti-nociceptive activities of hydroalcoholic extract and its various fractions from Adiantum capillus veneris Linn. J Ethnopharmacology, 138(3), 2011, 741-747

30. Hansel TT, Barnes PJ (2003) An atlas of chronic obstructive pulmonary disease: COPD. A resource for reference, teaching and lecturing (1st edn) London: Taylor \& Francis.

31. Khodaie L, Esnaashari S, Bamdad Moghaddam S. (2015). Essential Oil of Arial Parts of Adiantum capillus-veneris: Chemical Composition and Antioxidant Activity. J Nat Pharm Prod, 10(4):3-7.

32. Nilforoushzadeh MA, Javanmard SH, Ghanadian M. (2014). The Effects of Adiantum capillus - veneris on wound healing : An experimental in vitro evaluation. Int J Prev Med, 5(10):1261-8.

33. Kumar A. (2009). Antioxidant Effect of Adiantum Capillus Veneris Linn. On human lymphocyte : an in vitro study. J Cell Tissue Res, 9:1899-902. 
34. Pourmorad F, Hosseinimehr SJ and Shahabimajd N. Antioxidant activity, phenol and flavonoid contents of some selected Iranian medicinal plants. African Journal of Biotechnology, 5(11), 2006, 1142-1145.

35. Lin YR, Ding LJ. Extraction and determination on clearance rate of hydroxyl radicals of flavonoid from Adiantam capillusveneris. Food, 24, 2008, 63-66.

36. Clinical Characteristics of 138 Hospitalized Patients With 2019 Novel

Coronavirus-Infected Pneumonia in Wuhan, China - JAMA, Wang et al., February 7, 2020.

37. Hussain MM, Muthuprasanna $P$, Srinivasarao $T$, Velraj $M$, Shanmugapandian $P$ and

Suriaprabha K. Analgesic and antiinflammatory activity of Adiantum venustum. Res Rev

Biosci, 2, 2008, 102-104

38. Haider S, Kharbanda C, Alam MS, et al. (2013). Anti-inflammatory and anti-nociceptive activities of two new triterpenoids from Adiantum capillus-veneris Linn. Nat Prod Res,

27(24):2304-10.

39. Zhu X, Ge Y, Wu T, et al. Co-infection with respiratory pathogens among COVID-2019 cases [published online ahead of print, 2020 May 11]. Virus Res. 2020;285:198005.

Doi:10.1016/j.virusres.2020.198005

40. Ishaq MS, Hussain MM, Afridi MS, et al. (2014). In vitro phytochemical, antibacterial, and antifungal activities of leaf, stem, and root extracts of Adiantum capillus veneris.

ScientificWorldJournal, 2014:269793.

41. Singh M, Singh N, Khare PB and Rawat AKS. Antimicrobial activity of some important Adiantum species used traditionally in indigenous systems of medicine. J Ethnopharmacol, $115,2008,327-329$.

42. Husson GP, Vilagines $R$ and Delaveau P. Research into the antiviral properties of some natural extracts. Ann Pharm Fr, 44, 1986, 41-48.

43. Carod-Artal FJ. Neurological complications of coronavirus and COVID-19.

Complicaciones neurológicas por coronavirus y COVID-19. Rev Neurol.

2020;70(9):311-322. Doi:10.33588/rn.7009.2020179

44. Jain SK, Singh T, Pande M, Nema N. (2014). Neuropharmacological screening of fronds of Adiantum capillus veneris linn. Pharm Lett, 6(3):167-75.

45. Shin YK, Sohn UD, Choi MS, Kum C, Sim SS, Lee MY. Effects of rutin and harmaline on rat reflux oesophagitis. Autonomic and Autacoid Pharmacology, 22, 2002, 47-55.

46. Han C, Duan C, Zhang S, et al. Digestive Symptoms in COVID-19 Patients With Mild Disease Severity: Clinical Presentation, Stool Viral RNA Testing, and Outcomes [published online ahead of print, 2020 Apr 15]. Am J Gastroenterol.

2020;10.14309/ajg.0000000000000664. doi:10.14309/ajg.0000000000000664

47. Janbaz KH, Hassan W, Mehmood MH, Gilani AH. (2015). Antidiarrheal and antispasmodic activities of adiantum capillus veneris L. Bangladesh $\mathrm{J}$ Pharmacol, 10(1):222-29.

48.

https://www.idf.org/aboutdiabetes/what-is-diabetes/covid-19-and-diabetes/1-covid-19-and-di abetes.htm. international diabetes federation. COVID-19 and diabetes.

49. Ranjan V, Vats M, Gupta N, Sardana S. (2014). Antidiabetic potential of whole plant of Adiantum capillus veneris linn. in streptozotocin induced diabetic rats. IJPCR, 6(4):341-47. 50. Sultan AH, Dizaye KF, Hiwa BB. (2012). Histological, Immunocytochemical and Biochemical Study of the Effect of Adiantum Capillus on Alloxan Induced Diabetic Rats. MEJIM, 5:3-12. 
51. Kasabri V, Al-Hallaq E, Bustanji Y, et al. (2017). Antiobesity and antihyperglycaemic effects of Adiantum capillus-veneris extracts: in vitro and in vivo evaluations. Pharm Biol, 55(1):164-172.

52. Galehdari H, Negahdari S, Kesmati M, Rezaie A, Shariati G. (2016). Effect of the herbal mixture composed of Aloe Vera, Henna, Adiantum capillus-veneris, and Myrrha on wound healing in streptozotocin-induced diabetic rats. BMC Complement Altern Med, 16:386. 53. Peng YD, Meng K, Guan HQ, et al. Zhonghua Xin Xue Guan Bing Za Zhi. 2020;48(0):E004. Doi:10.3760/cma.j.cn112148-20200220-00105

54. Simonnet A, Chetboun M, Poissy J, et al. High prevalence of obesity in severe acute respiratory syndrome coronavirus-2 (SARS-CoV-2) requiring invasive mechanical ventilation [published online ahead of print, 2020 Apr 9]. Obesity (Silver Spring).

2020;10.1002/oby.22831. doi:10.1002/oby.22831

55. Chimie RRD, Al-hallaq EK, Litescu SC, et al. (2015). Hypocholesterolemic Effects of Adiantum Capillus Veneris L. aqueous extract in high Cholesterol diet-fed rats and hplc-ms determination of its polyphenolics. Rev Roum Chim, 60(4):357-65.

56. Coronavirus: Kidney Damage Caused by COVID-19, jhon hopkins medicine,C.JohnSperati,M.D.,M.H.S.

https://www.hopkinsmedicine.org/health/conditions-and-diseases/coronavirus/coronavirus-ki dney-damage-caused-by-covid19

57. Kanchan G. (2013). Protective effect of Adiantum capillus against chemically induced oxidative stress by cisplatin. J Appl Pharm Sci, 3(2):65-68.

58. Ahmed A, Wadud A, Jahan N, et al. (2013). Efficacy of Adiantum capillus veneris Linn in chemically induced urolithiasis in rats. J Ethnopharmacol, 146(1):411-16.

59. Ahmed A, Bilal A, Hajera S, Jahan N, Wadud A. (2013). In vitro effect of hydro alcoholic extract of Adiantum capillus-veneris Linn. On calcium oxalate crystallization. IJGP,

7(2):106-110.

60. Bhasin S., Brito J.P., Cunningham G.R. Testosterone therapy in men with Hypogonadism: an Endocrine Society clinical practice guideline. J Clin Endocrinol Metab. 2018;103:1715-1744.

61. Maria Schroeder, Berfin Tuku, Dominik Jarczak, Axel Nierhaus, Tian Bai, Henning Jacobsen, Martin Zickler, Zacharias Mueller, Stephanie Stanelle-Bertram, Andreas Meinhardt, Jens Aberle, Stefan Kluge, Guelsah Gabriel. The majority of male patients with COVID-19 present low testosterone levels on admission to Intensive Care in Hamburg, Germany: a retrospective cohort study. Medrxiv. Doi:

https://doi.org/10.1101/2020.05.07.20073817. Published online on 11 May 2020.

62. Andy Goren MD Sergio Vaño-Galván MD Carlos Gustavo Wambier MD, PhD John McCoy PhD Alba Gomez-Zubiaur MD Oscar M. Moreno-Arrones MD Jerry Shapiro MD Rodney D. Sinclair MD Michael H. Gold MD Maja Kovacevic MD Natasha Atanaskova Mesinkovska MD Mohamad Goldust MD Ken Washenik MD, PhD. A preliminary observation: Male pattern hair loss among hospitalized COVID-19 patients in Spain - A potential clue to the role of androgens in COVID-19 severity. First published:16 April 2020. https://doi.org/10.1111/jocd.13443.

63. Wambier CG, Vaño-Galván S, McCoy J, Gomez-Zubiaur A, Herrera S,Hermosa-Gelbard Á, Moreno-Arrones OM, Jiménez-Gómez N, González-Cantero A, Pascual PF,Segurado-Miravalles G, Shapiro J, Pérez-García B, Goren A, Androgenetic Alopecia Present in theMajority of Hospitalized COVID-19 Patients - the "Gabrin sign", Journal of the American Academy of Dermatology (2020), doi: https://doi.org/10.1016/j.jaad.2020.05.079. 
64. Noubarani M, Rostamkhani H, Erfan M, Kamalinejad M, Eskandari MR, Babaeian M and Salamzadeh J. (2014). Effect of Adiantum capillus veneris linn on an animal model of testosterone-induced hair loss. Iran J Pharm Res, 13(Suppl):113-8.

65. CDC. Human infection with 2019 novel coronavirus person under investigation (PUI) and case report form. Atlanta, GA: US Department of Health and Human Services, CDC; 2020.

66. World health organization,Multisystem inflammatory syndrome in children and adolescents temporally related to COVID-19

https://www.who.int/news-room/commentaries/detail/multisystem-inflammatory-syndrome-inchildren-and-adolescents-with-covid-19.

67. Swaroop Kumar K, Anbu J, Anjana A, et al. (2012). Influence of ethanolic leaf extract of Sargassum wightii and Adiantum capillus on histamine induced asthma in animal model. Int J Pharm Pharm Sci, 4(Suppl 4):121-23.

68. Aqhili Khorasani MH. Makhzan Al-Adviyah. Islamic Revolution Publications and Training Organization. Qom, Iran 1992.

69. Ansari Shirazi A. Ekhtiyarat-e Badiee. Pakhsh Razi Company Publications. Tehran, Iran 1992.

70. Dioscorides P. Alhashayesh. Trans. Tabatabaie SM. The Written Heritage Research Institute. Tehran, Iran 2013.

71. Ibn Al-Nafis. Al-Shamel fi Sanaat Al-Tebieh. Central Library of University of Tehran Publications. Tehran, Iran 2013.

72. Alwan AH, Al-Gaillany KAS, Naji A. (1989). Inhibition of the binding of 3 h-benzo [a] pyrene to rat liver microsomal protein by plant extracts. Int J Crude Drug Res, 27(1):33-37.

73. Shirazi ZA. (1992). Ikhtiyarat-e-Badiyee (Selections for Badii). Tehran: pakhsh razi press.

74. Rhazes (2005). Al Havi (Liber Continent). Tehran: Academy of Medical Sciences.

75. Medrar Hussain M, Ahmad B, Rashid E, et al. (2014). In vitro antibacterial activity of methanol and water extracts of Adiantum capillus veneris and tagetes patula against multidrug resistant bacterial strains. Pak J Bot, 46(1):363-68.

76. Shirazi MH, Amin G, Lavasani BA, Eshraghi SS. (2011). Study of antibacterial properties of Adiantum capillus-veneris extract on eight species of gram positive and negative bacteria. J Med Plants, 10(40):124-32.

77. Matsumoto M, Kotani M, Fujita A, Higa S, Kishimoto T, Suemura M and Tanaka T. Oral administration of persimmon leaf extract ameliorates skin symptoms and transepidermal water loss in atopic dermatitis model mice, NC/Nga. Br J Dermatol, 146, 2002, 221-227. 78. Coon N. The Dictionary of useful plants, Emmaus, Rodale Press, Leicestershire, UK 1974. 33.

79. Aghili Khorasani Shirazi MH. (1992). Makhzan ol Advieh (The Storehouse of Medicaments). Tehran: Tehran University of Medical Sciences. Sahba Press.

80. Yuan Q, Zhang X, Liu Z, Song S, Xue P, Wang J and Ruan J. Ethanol extract of Adiantum capillus-veneris $L$. suppresses the production of inflammatory mediators by inhibiting NF-kB activation. J Ethnopharmacol, 147(3), 2013, 603-611.

81. Yuan QY, Ruan JL, Cai YL. 2010. Effect of water extracts of Adiantum capillus-veneris Linn on UTI. Chin pharm J, 45(18):1389-92.

82. Vijayalakshmi A, Kiran Kumar Y. (2013). Evaluation of goitrogenic and antithyroidal effect of the fern Adiantum capillus-veneris. Rev Bras Farmacogn, 23(5):802-10

83. Ranjan V, Vats M, Gupta N, Sardana S. (2014). Antidiabetic potential of whole plant of Adiantum capillus veneris linn. In streptozotocin induced diabetic rats. IJPCR, 6(4):341-47. 
